\title{
ALGUMAS REFLEXÕES FRENTE A ATUAÇÃO DO SERVIÇO SOCIAL NA POLÍTICA DE EDUCAÇÃO NO MUNICÍPIO DE MATINHOS-PR
}

Lidiane Martins Rodrigues de Souza e Adriana Lucinda de Oliveira

RESUMO: O presente artigo tem como objetivo central analisar o processo de inserção do Serviço Social na política de educação no Município de Matinhos. A sistematização é fruto do estágio curricular do Curso de Serviço Social que possibilitou a identificação da necessidade de documentar, e publicizar esta atuação que é ainda recente no município. O trabalho apresenta a trajetória do Serviço Social no campo da educação, bem como o percurso traçado no município de Matinhos, que conta com esse profissional desde 2013 na Secretaria de Educação. A sistematização do processo de implantação do serviço ocorreu por meio de entrevistas semi-estruturadas com os principais profissionais envolvidos. A pesquisa demonstrou a premência do trabalho do Serviço Social na política de educação, espaço privilegiado de interlocução com as famílias e de orientação quanto ao acesso e defesa dos direitos sociais.

Palavras-chave: Serviço Social; Política de Educação; Estágio Curricular.

\section{INTRODUÇÃO}

O presente artigo tem como objetivo central analisar o processo de inserção do Serviço Social na política de educação no Município de Matinhos. A sistematização é fruto do estágio curricular do Curso de Serviço Social que possibilitou a identificação da necessidade de documentar, e publicizar esta atuação que é ainda recente no município. A realização de estágio curricular em Serviço Social possibilitou a identificação da necessidade de documentar e historicizar o início da intervenção dessa área na política de educação.

O trabalho apresenta a trajetória do Serviço Social no campo da educação, bem como o percurso traçado no município de Matinhos, que conta com esse profissional desde 2013 na Secretaria de Educação.

A sistematização do processo de implantação do serviço ocorreu por meio de entrevistas semiestruturadas com as três profissionais envolvidas, bem como com o gestor dessa pasta no momento da implantação do Serviço Social na referida secretaria. 
O artigo está estruturado em quatro seções. A introdução que apresenta a problemática, bem como os aspectos metodológicos da pesquisa. A segunda seção que apresenta os principais aportes teóricos do estudo. A terceira seção apresenta as principais reflexões realizadas a partir do objetivo central do estudo. A quarta seção apresenta as principais considerações finais.

\section{REVISÃO DE LITERATURA}

O Serviço Social na política de educação no Brasil, em algumas descrições é mencionado como um campo novo na atuação do/a assistente social. Em outras é citado como existente desde o surgimento da profissão no Brasil em 1930. Amaro (2012) afirma que há registro que o estado do Rio Grande do Sul em 1946 foi o pioneiro na inserção do Serviço Social Escolar, sendo implantado como serviço de assistência ao estudante, intervindo em situações escolares consideradas como desvio, defeito ou anormalidade social. Sendo assim, a ação do/a assistente social era voltada à adaptação dos/as alunos/as e ao equilíbrio social da comunidade escolar. A partir dos anos 1970 a intervenção no espaço educacional passa a ser voltado à preparação do indivíduo para a lógica capitalista. Com o movimento de reconceituação do Serviço Social ${ }^{1}$, que significou a tentativa de ruptura com o conservadorismo ${ }^{2}$ e a transição para um método crítico e investigativo, os profissionais passaram a ter outros referenciais para a intervenção e compreensão da realidade social. As ações do/a assistente

\footnotetext{
${ }^{1}$ O Movimento de Reconceituação do Serviço Social, iniciado na década de 1960, representou uma tomada de consciência crítica e política dos assistentes sociais em toda a América Latina, não obstante, no Brasil as condições políticas em que ele ocorreu trouxe elementos muito diversos dos traçados em outros países. As restrições da Ditadura Militar, principalmente depois do Ato Institucional $n^{\circ} 5$ (Barros, 1997, p.42), trouxeram elementos importantes nos rumos tomados pelo Serviço Social em seu processo de renovação. Esses profissionais, mediante o reconhecimento de intensas contradições ocorridas no exercício profissional, que se apoiava na corrente filosófica positivista, de Augusto Comte, questionavam seu papel na sociedade, buscando levar a profissão a romper com a alienação ideológica a que se submetera. Suas expectativas e desejos voltavamse para a busca da identidade profissional do Serviço Social e sua legitimação no mundo capitalista. Para tanto, uma nova proposta teórico-ideológica deveria alicerçar o ensino da profissão, originando uma prática não assistencialista, mas transformadora, comprometida com as classes populares. Quando o modelo filosófico elaborado por Karl Marx, passou a embasar o referencial teórico-metodológico do Serviço Social, o chamado materialismo Histórico Dialético. (PIANA, 2009, p.95).

${ }^{2} \mathrm{O}$ conservadorismo como forma de pensamento e experiência prática é resultado de um contramovimento de avanços da modernidade, e nesse sentido suas reações são restauradoras e preservadoras, particularmente da ordem capitalista. (YASBEK, 2009, p.5).
} 
social a partir da década de 1980 eram realizadas "através da articulação social com os Círculos dos Pais e Mestres (CPMs), Conselhos Tutelares, Grêmios Estudantis, Conselhos Escolares e da ação integrada entre professores e a equipe multiprofissional disponível na "rede" social já inventariada" (Amaro, 2012, p. 22). Para Pereira e Teixeira (2013, p.115) "o trabalho em redes surgiu como uma proposta de intervenção capaz de forjar uma nova abordagem no enfrentamento das demandas da população, baseada na troca de saberes e práticas entre o Estado, as empresas privadas e a sociedade civil organizada".

Piana descreve que:

No processo de ruptura com o conservadorismo, o Serviço Social passou a tratar o campo das políticas sociais, não mais no campo relacional da demanda da população carente e oferta do sistema capitalista, mas acima de tudo como meio de acesso aos direitos sociais e à defesa da democracia (PIANA, 2009, p.86).

A partir da década de 1990 as equipes técnicas passaram a atuar como equipe de saúde escolar, desta forma, as demandas pertinentes aos médicos, nutricionista e psicólogos passaram a contar com a abordagem do assistente social. A partir desta década além das demandas já colocadas ao assistente social emergiam outras demandas como: alunos/as usuários de drogas, crianças e adolescentes grávidas, alunos/as vítimas de maus tratos ou abuso sexual, déficit nutricional, depressivos ou crianças com necessidades especiais. Percebe-se que ao longo das décadas as demandas vão tomando outros formatos. As mesmas são expressões da questão social, e entende-se que conforme a realidade social, essas vão se modificando e sendo expressas de diferentes formas. Paralamamato:

Questão social apreendida como o conjunto das expressões das desigualdades da sociedade capitalista madura, que tem uma raiz comum: a produção social é cada vez mais coletiva, o trabalho tornase mais amplamente social, enquanto a apropriação dos seus frutos mantém-se privada, monopolizada por uma parte da sociedade. (IAMAMOTO, 2000, p.27)

A questão social se expressa no cotidiano familiar em diferentes aspectos como desemprego, violência doméstica, drogadição, alcoolismo, falta de escolaridade entre outras, que são trazidas e vivenciadas pelos/as alunos/as no ambiente escolar e familiar. O/A assistente social nesta conjuntura exerce sua 
atuação no enfrentamento da questão social, na orientação e defesa de direitos sociais, efetivados por meio de políticas públicas ${ }^{3}$.

A escola é considerada um dos principais equipamentos sociais, já que no cotidiano não se expressa somente à relação professor/a $x$ aluno/a e sim professor/a, aluno/a, famílias, todos os profissionais que atuam no ambiente escolar e comunidade. Neste contexto cada um apresenta sua particularidade ou individualidade, manifestando sua realidade neste ambiente. Deste modo o assistente social intervém identificando fatores sociais, culturais e econômicos "que determinam os processos que mais afligem o campo educacional no atual contexto" (CFESS, 2001). Esses fatores são expressos através da evasão escolar, baixo rendimento escolar, atitudes e comportamentos agressivos e de risco.

Segundo CFESS (2012, p.16) "a educação é um complexo constitutivo da vida social, que tem uma função social importante na dinâmica da reprodução social, ou seja, nas formas de reprodução do ser social". A escola é um espaço contraditório que pode instigar o estudante a ser um sujeito de pensamento crítico ou o inverso.

Neste contexto o/a assistente social comprometido com os princípios éticos da profissão contribui no ambiente escolar, para que haja autonomia e emancipação dos sujeitos através de orientações, palestras e projetos com os pais/mães, alunos/as, professores e toda comunidade, na articulação para que tenham acesso e luta pela garantia de acesso aos direitos sociais por meio de políticas públicas, na instrução sobre a liberdade de escolha sem opressão ou dominação, na formulação de projetos que busquem a redução de preconceitos e estimulem o respeito a diversidade.

A dimensão da atuação do Serviço Social na área da educação visa à garantia de participação da comunidade escolar na gestão democrática da

\footnotetext{
${ }^{3}$ As políticas públicas resultam de reações do Estado diante ao amplo rol de necessidades dos cidadãos que compõem uma sociedade. Podem ser desenvolvidas por meio de várias ações, tais como, diagnóstico das necessidades, criação de normas concernentes, estabelecimentos de prestações públicas e criação ou organização de instituições, com pessoal apto para implementá-las, direta ou indiretamente. O fim último da política pública nada mais é do que a concretização dos Direitos Humanos, garantindo a efetivação dos direitos individuais e coletivos, com vistas à emancipação política e econômica dos indivíduos, na perspectiva do desenvolvimento social. (FRIEDRICH, T. S., FRIEDRICH, N. M., 2014, p. 413).
} 
instituição, viabilizando estratégias para que alunos/as, pais/mães, professores/as e comunidade possuam o conhecimento dos espaços que thes garante o poder de voz, de escolhas, de participação da gestão, e da qualidade da educação, um exemplo desses espaços são os conselhos de políticas públicas. Deste modo o profissional atua na perspectiva de uma educação que contribua para a emancipação dos sujeitos. Esta dimensão não envolve apenas o aluno e sim toda a comunidade. As ações dos/as assistentes sociais constituem-se nas competências teórico-metodológico, ético-político, técnicooperativa. A dimensão teórico-metodológica compreende a relação teóricoprática, na perspectiva de superar o senso comum e perceber que teoria e prática são dimensões indissolúveis. A competência ético-político consiste na não neutralidade do/a profissional, que deve sempre posicionar-se politicamente diante da realidade apresentada, se respaldando no Código de Ética Profissional, respeitando e reconhecendo os valores, a cultura, costumes, a etnia, religião, relações de gênero, a sexualidade e identidade de cada pessoa; e a dimensão técnico-operativo consiste que o/a profissional conheça e apropriese de habilidades para a intervenção da realidade apresentada através de entrevistas, visitas domiciliares, reuniões, planejamento, avaliações, relatórios e encaminhamentos. O desafio cotidiano é justamente a articulação dessas três dimensões no fazer profissional.

A inserção do Serviço Social na política de educação tem a potencialidade de contribuir na redução da infrequência e evasão escolar que é a matéria do Projeto de Lei №. 3.688, em consonância com a luta pela democratização da educação, bem como de evidenciar a escola enquanto espaço de fortalecimento do processo de organização comunitária, de veiculação da informação e orientação quanto aos direitos sociais, defesa do acesso e usufruto de direitos, co-participação e co-responsabilização pelas crianças e adolescentes. Este projeto de lei está para ser aprovado pela Câmara dos Deputados desde novembro de 2000. Esta lei dispõe sobre a inserção do/a assistente social no quadro de profissionais de educação em cada escola. A proposição deste projeto de lei foi elaborado pelo Deputado José Carlos EliasPTB/ES, apresentado no dia 31 de outubro do ano de 2000, e dispõe sobre a 
inserção do/a assistente social no quadro dos/as profissionais em escolas públicas, tendo como função o acompanhamento dos/as alunos/as na escola e em sua comunidade. Após a implementação desta lei será estipulado um período gradual de cinco anos para que seja realizada esta inserção, a justificativa para que se efetive esta lei é a constante taxa de evasão e repetência escolar no Ensino Fundamental, relacionados às precárias condições socioeconômicas e culturais das famílias (BRASIL, 2000).

O/a assistente social inserido no campo educacional tem a atribuição de fazer mediações entre o/a aluno/a $x$ escola, estas intervenções estão relacionadas às infrequências e evasão escolar, violência doméstica, negligência, trabalho infantil, alcoolismo, drogadição.

Amaro (2012) acredita que para o enfrentamento da evasão e repetência escolar deve-se partir não só do investimento do prazer de estudar, mas também investir no desejo e nos sonhos de diferenciação social, mas para isso é necessário à construção de uma metodologia que fortaleça este investimento e que a mesma contribua para a diminuição da evasão e repetência escolar.

Essas ações podem ser realizadas através de rodas de conversas, palestras ou reuniões. Neste ambiente pode ser exposto pelo o/a assistente social temas como gênero, preconceito, adversidade, etnia, espiritualidade, ações afirmativas, entre outros; mas para não ficar apenas no senso comum é necessário aprofundar-se na história que perpassa o tema a ser trabalhado.

Dentre as várias temáticas as ações afirmativas, em especial as cotas é um assunto que causa muito preconceito, até mesmo pelo próprio cotista que muitas vezes não (re)conhece todo o processo histórico. A maioria dos estudantes acreditam que é uma vantagem ou privilégio participar das cotas, mas não compreendem que é um direito constituído para diminuir toda injustiça causada ao longo do tempo. A escola como espaço social deve esclarecer desde as séries iniciais questões como as cotas, desvelar para as crianças/adolescentes todo processo histórico até a constituição das cotas na atualidade, considerando que muitos alunos não sabem que tem o direto a cota por ter estudado em escola pública ou por serem negros/ pardos ou indígenas. 
A maioria dos/as pais/mães não têm o conhecimento dos direitos de seus filhos/as. Acredita-se que quando certas temáticas são trabalhadas com as crianças desde cedo, nota-se que há possibilidade de ressignificar, de questionar e desnaturalizar aspectos que são socialmente construídos, já que as crianças não nascem preconceituosas, mas refletem o que presenciam. Mesmo a escola sendo laica, a expressão de crenças no ambiente escolar é notável, o preconceito com a religião alheia, acreditando que apenas uma religião é merecedora de divindade. Independente da religião é dever de todos respeitar a crença da outra pessoa e no que ela acredita. Outra questão a ser trabalhada é gênero, até porque mesmo estando no século XXI muitas pessoas não tem entendimento do que é gênero ${ }^{4}$, e que gênero se trata de "feminino ou masculino", no ambiente escolar é possível organizar encontros com os pais/mães e alunos/as para o esclarecimento/debate sobre gênero, pois o preconceito contra o gênero feminino também parte da própria mulher que não tem a consciência de sua condição social construída historicamente.

Santos, Sousa e Fernandes (2016) trazem reflexões sobre as implicações e contribuições de experiências na educação popular e educação no campo. Estas reflexões partem da proposta política e pedagógica das Escolas do Campo do Movimento dos Trabalhadores Rurais Sem Terra (MST) do Estado do Ceará. As escolas do campo expressam-se a partir de lutas de classes e da necessidade de uma reforma agrária popular. A educação no MST é abordada como prioridade para construção de processos emancipatórios e progressistas dos sujeitos. As bases curriculares são denominadas de estudo, projeto e pesquisa, práticas sociais comunitárias, organização para o trabalho e técnicas produtivas que articulam com as matrizes pedagógicas formativas que são trabalho, história, cultura, organização coletiva e das lutas sociais sustentadas sob bases críticas e coletivas, que incentivam o sujeito a refletir, debater, intervir e buscar transformar sua realidade.

A Escola do Campo é a manifestação expressa das conquistas tecidas no coletivo da classe trabalhadora, que contraposta ao modelo vigente de organização social capitalista tem se articulado entorno de esforços

4 "Ele não apenas faz referência ao significado homem/mulher; ele também o estabelece". (LOPONTE, 2005, p.92) 
e lutas para o confronto da lógica, que visa transformar a vida em mercadoria (SANTOS; SOUSA; FERNANDES. 2016. não paginado).

A educação tem o papel de socializar o conhecimento, deste modo tanto a educação do campo como a educação popular tem o propósito de instigar, tecer a consciência crítica e sensibilizar os sujeitos por meio da educação em busca de igualdade de direitos, independência e menos opressão. Essa perspectiva está em profunda sintonia com o projeto ético político do Serviço Social tem como princípio à luta para construção de uma sociedade igualitária e justa sem dominação, sem exploração de classe, etnia ou gênero.

O campo educacional é um espaço contraditório onde são reproduzidas concepções, pensamentos, ideologias e possui diferentes projetos. Segundo Oliveira (2015)a educação está voltada para satisfazer e suprir as necessidades capitalistas, ou seja, está a priori a serviço do capital, objetivando formar uma massa trabalhadora para alimentar cada vez mais o mercado de trabalho e do lucro. Essa educação alinhada aos interesses do capital culpabiliza os indivíduos pelo fracasso ou sucesso no mercado de trabalho, individualizando os resultados com critérios meritocráticos e excludentes.

Na maioria das vezes o diploma não tem a mesma repercussão para o negro como para o branco, para o egresso da classe média ou classe média alta, pois o mercado de trabalho, para além do currículo, analisa a cor dos sujeitos, suas vestimentas, sua conduta através da Certidão Negativa de Antecedente Criminal, sua moral por meio de entrevistas, local onde reside, a formação familiar, se tem filhos ou pretende ter.

A educação tem a potencialidade de transformação ou conscientização dos indivíduos, mesmo que o sistema educacional seja produzido no e pelo sistema capitalista e a modificação deste sistema seja demorada, é possível algum avanço através de iniciativas, como a instituição estabelecer um PPP diferenciado, e o corpo docente/técnico estimular o pensamento crítico a fim de empoderar os sujeitos. É necessário que o/a assistente social defenda e lute para que estabeleça um projeto de educação que contemple a crítica ao status quo, a análise da conjuntura, a percepção das determinações sociais, políticas ideológicas e econômicas presentes no cotidiano da escola. Nesta perspectiva, 
defendemos que o/a Assistente Social no âmbito escolar tem a capacidade de construir em parceria com os demais profissionais, técnicos, alunos/as, familiares e comunidade um outro projeto de educação, pautado na crítica, em defesa dos direitos sociais, da autonomia, da cidadania.

\section{O PROCESSO DE INSERÇÃO DO SERVIÇO SOCIAL NA POLÍTICA DE EDUCAÇÃO DO MUNICÍPIO DE MATINHOS: A PARTIR DOS RELATOS DOSIAS PROFISSIONAIS ENVOLVIDOSIAS.}

A sistematização do processo de inserção do profissional de Serviço Social na política de Educação de Matinhos, ocorreu através de entrevistas semiestruturadas com o secretário da pasta no momento da implantação (2013), bem como com as duas primeiras assistentes sociais que desenvolveram esse trabalho até e com a profissional que está desde 2016 a frente dessa política.

O início do trabalho do Serviço Social na secretaria de educação do município ocorreu devido à decisão política do secretário desta pasta, que em 2013 foi convidado pelo prefeito municipal para compor a gestão municipal. Em entrevista, o referido gestor (entrevistado 1) relatou que logo em sua chegada procurou construir um diagnóstico, na perspectiva de identificar as principais necessidades das escolas e da secretaria. Foram levantadas algumas demandas que deveriam ser trabalhadas com urgência, entre elas: capacitações para os/as professores/as, plano de carreira para os/as professores, estrutura física das escolas e atividades direcionadas para as famílias nas escolas.

O gestor da secretaria de educação da época nos relatou que as atividades direcionadas às famílias nas escolas fundamentavam-se na constatação da necessidade de uma maior aproximação das famílias ao espaço escolar, esclarecendo que a educação é um processo no qual a família tem uma centralidade, cabendo à escola ser parceira.

Outra demanda verificada nas escolas refere-se aos altos índices de evasão escolar sem justificativas ou faltas frequentes também não justificadas. Diante dessa situação, o secretário optou pela inserção de um/a profissional de Serviço Social, com a expectativa que o/a mesmo/a pudesse desenvolver um 
trabalho com as escolas e familiares, enfatizando o direito da criança de frequentar o espaço escolar e o dever da família em acompanhar este processo, desde frequência, atividades escolares e cuidados com a criança.

Ressaltamos que o cargo de Assistente Social está previsto no Plano Municipal de Educação do município, instrumento de gestão, elaborado com a participação da sociedade civil, onde estão contidos os objetivos e metas a serem alcançados pela política a curto, médio e longo prazo, num período de dez anos após sua promulgação. No Município de Matinhos o Plano Municipal de Educação cumprirá os dez anos em 2024.

O início do trabalho teve como foco o processo de evasão e infrequência escolares. A profissional que iniciou o trabalho elaborou documentos como "Convocação para o Comparecimento do Responsável", "Termo de Compromisso e Responsabilidade", "Termo de Visita", "Solicitação e acompanhamento Social" utilizados para o contato com as famílias, bem como para os encaminhamentos para outros equipamentos. Na perspectiva de articular um trabalho em rede, foi realizado visita a todos os equipamentos sociais como Centro de Referência da Assistência Social (CRAS), Centro de Referência Especializado de Assistência Social (CREAS), Assistência Social, Hospital, Conselho Tutelar, para possibilitar a apresentação da profissional na área referida e formar parcerias com os equipamentos mencionados.

Iniciou-se então um trabalho de monitoramento e enfrentamento das infrequências e evasão escolares, sistematizado através da notificação das diretoras das escolas e de uma acompanhamento dessas situações pelo Serviço Social, através de busca ativa, visitas domiciliares e encaminhamentos a rede de serviços. Além desse trabalho o Serviço Social passou a compor a equipe de outros três projetos:

Projeto Saúde na Escola (PSE) que tem a finalidade de fortalecer a promoção, prevenção e atenção à saúde, destinando-se ao enfrentamento da vulnerabilidade que compromete o desenvolvimento de crianças e jovens da rede pública de ensino. Projeto de prevenção ao Trabalho Infantil, que tem por objetivo promover a conscientização dos/as profissionais da escola, alunos/as, família e comunidade em perspectiva da erradicação do trabalho 
infantil e a proteção ao trabalhador adolescente. Projeto Saúde Bucal que tem por objetivo a orientação sobre a higienização bucal aos alunos/as de todas as escolas municipais.

Assim, o plano de trabalho da Assistente Social iniciou com os seguintes objetivos:

- Acompanhar os alunos da rede municipal de educação, regularmente matriculados no ensino regular do $1^{\circ}$ ao $5^{\circ} \mathrm{Ano}$, classe especial, sala de recursos e educação infantil, garantindo o acesso à educação e permanência na Escola.

- Fazer busca ativa dos alunos que não estão frequentando a Escola, bem como orientar quanto á transferências e procura por vagas, tanto dentro como fora do município de Matinhos.

- Realizar trabalho em rede com os demais órgãos, na garantia plena dos direitos da criança e adolescente.

- Auxiliar e orientar Escolas e CMEls, em questões conflituosas que envolvem a família dos alunos atendidos e a Educação.

- Atender de forma humanizada e sigilosa casos de violação de direitos da criança e do adolescente, realizando escuta sensível dos alunos.

- Encaminhar aos órgãos responsáveis todos os casos de violação de direitos da criança e do adolescente.

- Realizar palestras e atividades de prevenção e orientação com alunos e familiares, abordando as diversas expressões da Questão Social.

- Auxiliar o Programa Saúde na Escola.

O trabalho foi se estruturando e foi se evidenciando a complexidade e abrangência definida no plano de trabalho, traduzida nas dificuldades de um trabalho mais efetivo, considerando o número de escolas no município.

No momento, outubro de 2017, a secretaria de educação segue com apenas Assistente Social e três estagiários de Serviço Social. O trabalho tem buscado uma maior estruturação, bem como a delimitação da atuação numa perspectiva preventiva e informativa, considerando que uma intervenção mais sistemática nas escolas requer uma equipe maior. 
Para tanto, a profissional tem instituído protocolos de ações e projetos realizados com as famílias e profissionais das escolas no trabalho de prevenção, identificação e de encaminhamento de situações de riscos.

No momento os projetos em execução pelo Serviço Social da secretaria de educação são:

- Continuidade ao Projeto de Prevenção ao Trabalho Infantil em parceria com o Ministério Público do Trabalho; que ocorre através de ações sistematizadas no decorrer do ano letivo.

- Reunião Técnica com a Família. compreende um grupo de famílias para a orientação sobre as responsabilidades da família, bem como de acompanhamento e encaminhamento. As famílias que participam deste projeto são as que já foram atendidas pelo Serviço Social da educação e que apresentaram algum tipo de vulnerabilidade.

- Formação Continuada para Pais/Mães está sendo realizada através de encontro semestrais nas 8 Escolas Municipais e nos 15Centros Municipais de Educação Infantil CMEls. Esses encontros são organizados pela equipe de profissionais das escolas e objetiva uma abordagem sobre os direitos sociais das crianças, adolescentes e da família. Tem caráter informativo e preventivo.

- $\quad$ Formação Continuada para Profissionais da Escola foi iniciado com as atendentes dos Centros Municipais de Educação Infantil - CMEls. No ano de 2017 foram realizadas capacitações, para trabalhar a prevenção de riscos para violência e negligência por parte da escola e orientações sobre os encaminhamentos. O trabalho com as atendentes dos CMEls objetiva contribuir para um atendimento humanizado e acolhedor, já que atendem crianças da educação infantil (6 meses à 5 anos). A capacitação também atendeu profissionais que trabalham com crianças vinculadas ao ensino fundamental do projeto Saberes (contraturno social).O estabelecimento de vínculos com as crianças interferem de maneira significativa no desenvolvimento cognitivo, motor e na sociabilidade. Objetiva ainda instrumentalizar toda a equipe na identificação de maus tratos e negligência contra as crianças. 
- Enfrentamento a Evasão Escolar e Infrequência essa ação tem ocorrido a partir dos encaminhamentos da direção das escolas, sendo que o Serviço Social realiza busca ativa, através de visitas domiciliares, na perspectiva de identificar as dificuldades da família para a garantia do acesso ao direito a educação das crianças e adolescentes.

Para que haja compreensão sobre a importância da atuação por parte dos profissionais da educação e da comunidade está sendo realizado o trabalho de fortalecimento e (re) conhecimento do Serviço Social neste campo. Segundo Piana (2009, p.162):

O espaço do Serviço Social no cenário educacional ainda é pouco reconhecido, mas vem sendo gradativamente conquistado... Portanto o papel do assistente social no espaço escolar tende de ser aceito pelo coletivo escolar, à medida que ele constitui competências e habilidades em respostas às demandas do processo educativo.

Uma das principais dificuldades encontradas no cotidiano do trabalho, dá-se pela fragilidade do trabalho em rede no município, sendo que muitas vezes, as equipes dos próprios equipamentos sociais não possuem a compreensão da importância desta ação. Para Lussi e Marinucci:

\begin{abstract}
A simbologia da "rede" é significativa para a compreensão do conceito: a rede não é apenas a soma de cordas. É uma maneira de entrelaçar as cordas de tal modo que, juntas, conseguem adquirir potencialidades que ultrapassam as capacidades individuais de cada uma delas. Em outras palavras, o trabalho em rede, além de ser uma forma privilegiada para somar forças, é também uma maneira de trabalhar de forma articulada que permite desdobrar as habilidades dos sujeitos envolvidos, garantindo uma maior eficácia no trabalho e maior eficiência nos resultados. (LUSSI, MARINUCCI, 2007, p.1)
\end{abstract}

Entende-se que o trabalho em rede fortifica e potencializa as ações dos equipamentos nas realizações de projetos comuns. Para o benefício da população atendida, é necessário que a rede atue de forma articulada.

Entretanto, a tessitura da rede é um processo que requer mobilização, organização, envolvimento para estabelecer uma relação dialógica de troca, de reconhecimento, de valorização de cada participante da rede, estimulando o conhecimento crítico, a socialização das informações, o enfrentamento coletivo das dificuldades, a construção de estratégias, enfim a instrumentalização do 
processo, com vistas ao fortalecimento dos serviços públicos numa perspectiva intersetorial e interdisciplinar.

Uma abordagem interdisciplinar demanda a tentativa diária de superar a lógica fragmentada do conhecimento, respeitando as especificidades, enfatizando a troca, o aprendizado conjunto, a interação das diferentes áreas.Lisboa (2003) aponta para a necessidade de desenvolvermos um olhar multifacetário, afirma que:

Carecemos de um pensamento sincrético, polifônico, de perceber que estamos enredados (em-rede) em campos mais amplos que, tanto nos superam quanto são por nós construídos e que se transformam e nos transformam na medida em que nos transformamos, num circuito espiral (LISBOA, 2003, p.10).

Nessa perspectiva, além da ação de cada sujeito, é fundamental que os gestores das políticas públicas assumam a construção de um trabalho em rede, como estratégia de gestão, visando as interfaces entre setores e instituições governamentais (e não governamentais), bem como o enfrentamento de problemas sociais complexos que ultrapassam a alçada de um só setor de governo ou área de política pública(MONNERAT e SOUZA, 2014).

Nesta perspectiva, a recente inserção do profissional de Serviço Social na política de educação, com certeza, caracteriza-se em uma conquista e um ganho para a política pública. No entanto, os efeitos desse trabalho pode ser potencializado se o município tiver como estratégia de gestão um trabalho articulado em os diferentes setores, políticas e equipamentos sociais.

\section{CONSIDERAÇÕES FINAIS}

O presente artigo abordou as dificuldades, possibilidades e potencialidades da inserção do/a assistente social na política de educação. Observam-se avanços nesta discussão, principalmente na luta da própria categoria profissional para que seja efetivada essa atuação na política de educação, por meio da aprovação do Projeto de Lei $n^{\circ} 3.688 / 2000$. O referido projeto dispõe sobre a prestação de serviços de psicologia e de serviço social nas redes públicas de educação básica. 
A prefeitura municipal de Matinhos promoveu um grande passo com a inserção do Serviço Social na educação, considerando a contribuição da atuação do profissional neste espaço. Esta atuação teve algumas fragilidades na documentação e do registro, o que trouxe relevância para essa sistematização. As conquistas, ao longo da história, ocorreram por meio de lutas, documentos, registros, abaixo assinados, propostas de leis, estudos e pesquisa que foram evidenciando e reivindicando serviços e direitos.

Desta forma o presente artigo teve como objetivo documentar, registrar e publicizar o início do Serviço Social na política de educação através das declarações dos sujeitos que fizeram parte dessa trajetória. A aproximação dessa realidade ocorreu através do estágio curricular obrigatório em Serviço Social.

No quadro da literatura sobre o tema verifica-se que, a atuação profissional e a experiência de estágio é cercada de inúmera cobranças relacionadas à família e aos profissionais que tem suas responsabilidades, mas que também necessitam de acompanhamento e cuidados. Percebe-se que a família é muito cobrada, mas quem é que apoia esta família? Quais são as políticas que a mesma tem acesso? Essa família tem o acesso à educação, qualificação, saúde, moradia, transporte e trabalho? Há cobrança das escolas e dos professores. Afirma-se que os professores não estão preparados para lidar com a realidade extremamente complexa que a escola apresenta. Entretanto, os mesmos nem sempre possuem o respaldo necessário para enfrentar e mediar as diferenciadas demandas colocadas pelos estudantes e seus familiares.

Os demais equipamentos sociais ligados a outras políticas públicas como assistência social, saúde, habitação, trabalho e renda também não têm conseguido suprir, com qualidade, todos os serviços e atendimentos a esses destinados. Constata-se que os problemas relacionados à educação têm sido encarado de forma fragmentada e, portanto, não conseguem dar conta da sua complexidade.

Dessa forma, o debate acerca do trabalho em rede é reiterado como uma alternativa potencializadora no enfrentamento às diferenciadas expressões da questão social expressas no cotidiano das crianças e adolescentes, seja no 
âmbito da família ou no cotidiano escolar.

O presente artigo evidenciou que o percurso da inserção do profissional de Serviço Social na política de educação no município pesquisado foi um avanço, pois trouxe inúmeras contribuições para o enfrentamento dos problemas cotidianos da educação no município, como o enfrentamento do processos de evasão escolar, infrequência, negligência e violência contra as crianças e adolescentes. Todavia, há premência de um trabalho efetivamente articulado na gestão pública para que possamos almejar resultados mais efetivos na garantia de direitos com primazia da crianças e dos adolescentes.

Este estudo demonstrou que há necessidade de mais pesquisa com perspectiva intersetorial e interdisciplinar para dar suporte e amparado ao planejamento e gestão local. Uma abordagem interdisciplinar demanda a tentativa diária de superar a lógica fragmentada do conhecimento, respeitando as especificidades, enfatizando a troca, o aprendizado conjunto, a interação das diferentes áreas.

\section{REFERÊNCIAS}

AMARO, S. Serviço social na educação: bases para o trabalho profissional. Florianópolis. Ed. Da UFSC, 2012, p. 22.

CFESS. Serviço Social na Educação. 2001. Disponível em: <http://www.cfess.org.br/js/library/pdfjs/web/viewer.html?pdf=/arquivos/SS_na_ Educacao(2001).pdf>. Acesso em: 07/mai./17.

Educação. $2012 . \quad$ pg. 16.20 Disponível em:<http://www.cfess.org.br/js/library/pdfjs/web/viewer.html?pdf=/arquivos/BRO CHURACFESS_SUBSIDIOS-AS-EDUCACAO.pdf>. Acesso em: 07/05/17.

FRIEDRICH. T. S.; FRIEDRICH. N.M. Políticas Públicas, Direitos Humanos e Cidadania em Relação à Água. In: SILVA, E. F.; GEDIEL, J. A. P.; TRAUCZYNSKI, S. C. DIREITOS HUMANOS E POLÍTICAS PÚBLICAS. ED. Universidade Positivo. Curitiba. 2014. p. 413.

IAMAMOTO, M. V. O serviço social na contemporaneidade: trabalho e formação profissional. 3. Ed. - São Paulo, Cortez, 2000. p.27. 
LISBOA,A. M. Economia Solidária, economia barroca: a emergência da socioEconomia Solidária na América Ibérica. Portugal: Universidade Técnica de Lisboa, 2003 (tese de doutorado).

LOPONTE, L. G. Gênero, Educação e Docência nas Artes Visuais. Educação e Artes. Porto Alegre. v.30. n. ${ }^{\circ}$ 2. p.92. Jul./dez. 2005.

LUSSI, C.; MARINUCCI, R. Notas sobre trabalho em rede. Centro Scalabriniano de Estudo Migratório. Brasília. 2007. p.1. Disponível em: $<$ http://www.csem.org.br/pdfs/notas_sobre_trabalho_em_rede.pdf $>$. Acesso em: 10/06/17.

MONNERAT, G. L.; ALMEIDA, N. L. T.; SOUZA, Rosimary G. A intersetorialidade na agenda das políticas sociais. Campinas, SP: Papel Social, 2014. p. 105-123.

OLIVEIRA, A. L. O processo de inserção profissional dos egressos da UFPR Setor Litoral. 191 f. Tese (Doutorado em Políticas Públicas) Universidade Federal do Paraná. Curitiba. 2015. p.39.

PEREIRA, K. Y. L.; TEIXEIRA, S M. Redes e intersetoriedade nas políticas sociais: reflexões sobre sua concepção na política de assistência social. Textos e Contextos. Porto Alegre. V.12, n 1. p. 115. jan./jun. 2013. Disponível em:

http://revistaseletronicas.pucrs.br/fass/ojs/index.php/fass/article/view/12990. Acesso em: 05/04/17.

PIANA, M. C. A construção do perfil do assistente Social no cenário educacional. São Paulo. Editora UNESP.2009. p.86/95/162. Scielo Books. Disponível em: http://static.scielo.org/scielobooks/vwc8g/pdf/piana9788579830389.pdf. .Acesso em: 07/04/17.

SANTOS, J. F. A.; SOUSA, M. L. F.; FERNANDES, R. C. F. Serviço Social, Educação no Popular e do Campo: uma interlocução necessária na materialização do projeto ético político. In. Congresso Brasileiro de Assistentes Social. 15. 2016. Olinda. Anais... Olinda: SOB, 2016. 1 CD-ROM.

YASBEK, M. C. Os fundamentos históricos e teórico-metodológicos do Serviço Social brasileiro na contemporaneidade. In: CFESS (Org.). Serviço Social: Direitos Sociais e Competências Profissionais. 2009. Brasília /DF. p.5. (paginação irregular). 